\title{
Health-related quality of life and burden of illness in adults with newly diagnosed attention-deficit/hyperactivity disorder in Sweden
}

\author{
E. Ahnemark ${ }^{1 *}$, M. Di Schiena2 ${ }^{2}$ A.-C. Fredman ${ }^{2,8}$, E. Medin ${ }^{3,4}$, J. K. Söderling ${ }^{5}$ and Y. Ginsberg ${ }^{6,7}$
}

\begin{abstract}
Background: This observational, cross-sectional, retrospective chart review aimed to identify factors determining health-related quality of life (HRQoL) in adults with newly diagnosed attention-deficit/hyperactivity disorder (ADHD) in Sweden.

Methods: Adult participants with a new clinical diagnosis of ADHD were enrolled from two specialist outpatient clinics in Stockholm, Sweden, from 2013 to 2015. Data extracted from patient records included demographics, clinical characteristics and comorbid psychiatric diagnoses identified using the Mini International Neuropsychiatric Interview (MINI). Depression severity was assessed using the Montgomery-Åsberg Depression Rating Scale - Selfreported (MADRS-S). The self-rated five-dimension EuroQol questionnaire (EQ-5D) was used to measure HRQoL. Predictors of EQ-5D index score were identified using multivariate linear regression adjusting for age, sex, education level, and main income source.

Results: The mean age of the 189 enrolled patients was 35.2 years (standard deviation [SD], 12.3), and 107 (57\%) were female. Psychiatric comorbidities were present in 92 patients (49\%), with anxiety and depression being the most common diagnoses. The mean EQ-5D index score was 0.63 (SD, 0.28). Low EQ-5D index scores were significantly associated with high MADRS-S scores, multiple comorbid psychiatric disorders, low educational achievement, female sex, and not having a main income derived from employment or self-employment.

Conclusions: These findings suggest that adults with newly diagnosed ADHD experience low HRQoL, which may often be exacerbated by psychiatric comorbidities such as anxiety and depression. Patients presenting with ADHD and psychiatric comorbidities in adulthood may require particular care and resources in the management of their ADHD.
\end{abstract}

Keywords: ADHD, HRQoL, Psychiatric comorbidities

\section{Background}

Attention-deficit/hyperactivity disorder (ADHD) is estimated to affect between 2.5 and $5.0 \%$ of adults worldwide [1-3]. Although originally considered to be a disorder of childhood, ADHD is now recognized to persist into adulthood in approximately $65 \%$ of cases [4-7]. While many adults with newly diagnosed ADHD may have experienced symptoms as children [6], two recent studies have

\footnotetext{
* Correspondence: eahnemark@shire.com

'Shire, Vasagatan 7, SE-111 20 Stockholm, Sweden

Full list of author information is available at the end of the article
}

suggested that, in some cases, ADHD symptoms may not manifest until adulthood [8,9]. Results from a study in Sweden demonstrated that the number of adults diagnosed with ADHD increased year on year from 2006 to 2011 [10], and in 2013 ADHD was diagnosed in 2.7\% of adult psychiatric patients in Sweden [11]. Despite the increasing recognition of ADHD in the adult Swedish population, a recent registry study reported that patients with psychiatric symptoms may undergo years of treatment before receiving an ADHD diagnosis [11]. Nylander et al. found that diagnosis of ADHD in adults took, on average,

(c) The Author(s). 2018 Open Access This article is distributed under the terms of the Creative Commons Attribution 4.0 International License (http://creativecommons.org/licenses/by/4.0/), which permits unrestricted use, distribution, and reproduction in any medium, provided you give appropriate credit to the original author(s) and the source, provide a link to the Creative Commons license, and indicate if changes were made. The Creative Commons Public Domain Dedication waiver (http://creativecommons.org/publicdomain/zero/1.0/) applies to the data made available in this article, unless otherwise stated. 
3 years from the initial point of contact with psychiatric services, although in some cases diagnoses were delayed for as long as 10 years [11]. Delays in diagnosis were particularly apparent if the signs and symptoms of ADHD were attributed to other psychiatric disorders, for example, anxiety disorders, which often co-occur with ADHD [11]. These findings highlight the need for increased recognition and understanding of ADHD as an adult psychiatric disorder. Similarly, the European Network Adult ADHD published a consensus document in 2010, with the aims of increasing awareness of ADHD in adults and improving patient care across Europe [12].

The effects of ADHD can have a significant negative impact on many aspects of adult life, from social and emotional well-being to professional development and financial security $[13,14]$. Despite this, few studies have investigated the burden of disease in adult patients with ADHD. Swedish patient records and archives provide a rich source of data for investigating burden of illness in adults with newly diagnosed ADHD. The diagnostic procedure for adults comprises a clinical interview to assess the frequency and duration of ADHD symptoms, as well as a full neuropsychiatric investigation of functional impairments from both clinical and social perspectives. This retrospective chart review study utilized the five-dimension EuroQol questionnaire (EQ-5D) [15] to develop a predictive model of health-related quality of life (HRQoL) in adults with newly diagnosed ADHD, based on their ADHD symptoms, psychiatric comorbidities, and socioeconomic characteristics.

\section{Methods}

\section{Study design and conduct}

This study was an observational, cross-sectional, retrospective chart review of adult patients with newly diagnosed ADHD at one of two specialist neuropsychiatric outpatient clinics (Liljeholmen or Danderyd) in Stockholm, Sweden, between 2013 and 2015. The study was conducted in accordance with the ethical standards of the World Medical Association Declaration of Helsinki. The study was approved by the Regional Ethical Review Board in Stockholm and the need for consent was waived due to the retrospective nature of the study.

\section{Participants}

The study population was identified from electronic medical records (EMRs) and archives of patients' neuropsychiatric investigations from the two study sites. Only patients aged 18 years and above who underwent neuropsychiatric investigation and received a new and confirmed diagnosis of ADHD (International Statistical Classification of Diseases and Related Health Problems - 10th Revision, Swedish modification [ICD-10-SE] diagnosis code F90) [16] were enrolled in the study.

\section{Diagnostic investigations at Liljeholmen and Danderyd}

Extensive diagnostic investigations were conducted at outpatient clinics for all enrolled patients. Patients were interviewed alongside any family members or companions (usually parents or spouse), and details of their medical history, developmental history, coexistent disorders, and current condition were recorded. A medical examination, including blood tests and drug screening, was also part of the diagnostic process. During the neuropsychiatric investigation, the frequency and duration of patients' psychiatric symptoms were recorded, their functional impairments and cognitive and executive functioning were assessed, and routine diagnostic tests for psychiatric disorders were completed. Several different self-report scales, psychological tests, and structured interviews were used to provide a comprehensive neuropsychiatric evaluation and confirm the ADHD diagnosis (Table 1). ADHD-specific instruments included the Diagnostic Interview for ADHD in Adults, second edition (DIVA 2.0), and the Adult ADHD Self-Report Scale version 1.1 (ASRS-v1.1).

\section{Data extraction}

All patient-related information, including findings from the neuropsychiatric investigations, were accessed through EMRs and patient archives. Clinical researchers with knowledge and experience of treating patients with ADHD extracted anonymized patient data using data-gathering forms specifically designed for the study. The data-gathering form was based on the recommendations for neuropsychiatric investigations of patients with suspected ADHD described in recent guidelines (www.psykiatristod.se) and validated by a clinical expert.

The information extracted included social and clinical characteristics, patient and family histories, and details of any prescribed medication. Adult scores from the DIVA 2.0 and ASRS-v.1.1 Screener (6 items) and Symptom checklist (18 items) were also obtained (Table 1) [17].

Full details of any psychiatric diagnoses, made using the Mini International Neuropsychiatric Interview (MINI) Swedish version 6.0.0 [18], were also extracted from the databases. The MINI comprises a short structured interview in which patient symptoms and signs are assessed against diagnostic criteria given in the Diagnostic and Statistical Manual of Mental Disorders, fourth edition (DSM-IV) [19]. MINI-identified depression includes depressive episodes and recurrent depression (ICD-10-SE diagnosis codes F32-F33). MINI-identified anxiety includes phobias, other anxiety disorders and obsessive-compulsive disorder (ICD-10-SE, F40-F42). Autism was diagnosed separately as part of the neuropsychiatric investigation.

Other extracted data included patient-reported indications of drug and alcohol abuse, depression, and HRQoL (Table 1). HRQoL was assessed using the EQ-5D, and the Montgomery-Åsberg Depression Rating 
Table 1 Data extracted from electronic medical records and archives

\begin{tabular}{ll}
\hline Basic characteristics & Age, sex, type of referral, confirmed ADHD diagnosis, other psychiatric diagnoses (confirmed using MINI) \\
Social status & Marital status, parental status (biological), age of children, housing, education, main source of income \\
Patient history & Psychiatric history, previous confirmed psychiatric diagnoses, current registered somatic diagnoses \\
Family history & General and specific psychiatric and neuropsychiatric disorders in the family \\
Risk assessment & Previous suicide attempts, previous or current self-destructive, aggressive, or criminal behaviour \\
ADHD diagnostic interview & DIVA 2.0 (symptoms of attention deficit [A1] and hyperactivity/impulsivity [A2]) \\
Patient-reported measures & Scores for ASRS-v.1.1 Screener and Symptom checklist and AUDIT, DUDIT, MADRS-S, and EQ-5D \\
Intelligence assessment & WAIS-IV score \\
Pharmacological treatments & Current psychiatric and somatic medications, recommended ADHD medication after neuropsychiatric investigation
\end{tabular}

ADHD attention-deficit/hyperactivity disorder, ASRS-v.1.1 Adult ADHD Self-Report Scale version 1.1, AUDIT Alcohol Use Disorders Identification Test, DIVA 2.0 Diagnostic Interview for ADHD in Adults, second edition, DUDIT Drug Use Disorders Identification Test, EQ-5D five-dimension EuroQol questionnaire, MADRS-S Montgomery-Åsberg Depression Rating Scale - Self-reported, MINI Mini International Neuropsychiatric Interview, WAIS-IV Wechsler Adult Intelligence Scale IV

Scale - Self-reported (MADRS-S) screening instrument [20] was used to evaluate the presence and severity of depressive symptoms. For patients enrolled from the Liljeholmen clinic, MADRS-S scores were calculated from Patient Health Questionnaire 9 (PHQ-9) scores using a published regression equation (MADRS-S $=[1.206 \times$ PHQ-9] + 4.062) [21]

\section{Linear regression models}

Potential predictors of HRQoL were identified using a linear regression model of EQ-5D index score, adjusting for age $(18-29,30-39,40-49$, or $\geq 50$ years), sex, education (secondary/university or other), and main source of income (full- or part-time employment or other). A linear regression model with the same covariates was used to predict differences in EQ-5D index score between subgroups of patients with or without comorbid psychiatric diagnoses.

A multiple imputation model was employed to estimate values for missing data using five iterations per value. Covariates included in the imputation model were age, sex, study site, education, source of income, MINI-identified comorbid diagnoses, previously confirmed psychiatric disorders, previous suicide attempts, somatic diagnoses, current psychiatric medications, recommended ADHD medication after neuropsychiatric investigation, DIVA 2.0 scores, ASRS-v.1.1 scores, MADRS-S scores, and both EQ-5D index and visual analogue scale scores. Missing EQ-5D index scores were replaced for 27 patients (Additional file 1: Table S1). Patients aged 50 years or older and those recruited in Liljeholmen (as opposed to Danderyd) were more likely to have missing EQ-5D values. Although imputed values for these patients tended to be below the mean, the distributions of the observed and imputed EQ-5D index score data were similar. Multiple imputation was performed using SAS v9.3 software (SAS Institute, Cary, NC, USA).

\section{Statistical analysis}

Differences between study sites in mean patient age and the ratio of male to female patients were analysed using $t$-tests and $x^{2}$ tests, respectively $(\alpha=0.05)$. Data were analysed using SAS v9.3 (SAS Institute, Cary, NC, USA).

\section{Results}

\section{Demographics and patient characteristics}

The study enrolled 189 adult patients with newly diagnosed ADHD, of whom 57\% were women (Table 2). The mean patient age was 35.2 years (standard deviation [SD], 12.3), and ages ranged from 18 to 72 years. There was no statistically significant difference in mean patient age between the two clinics, but a significantly larger proportion of female participants were enrolled from Danderyd than from Liljeholmen $(p=0.04$; Table 2).

The majority of patients (114/189 [60\%]) had diagnoses of 'combined type' ADHD, while 49/189 (26\%) had 'predominantly inattentive type' and 26/189 (14\%) had 'unspecified type' (which includes either 'combined' type or 'predominantly inattentive' type; Table 2). Of the 189 patients, most did not reach a level of education beyond secondary school; $13 \%$ had a university education. Fewer than half of the patients listed employment as their main source of income, with $37 \%$ in full- or part-time employment and 10\% self-employed (either full- or part-time; Table 2).

\section{Clinical characteristics and treatment history}

Data extracted from the MINIs revealed that almost half of patients (92/189 [49\%]) had a psychiatric comorbidity (Table 3). Anxiety and depression were the most common, affecting 65/189 patients (34\%) and 37/189 patients (20\%), respectively. Both anxiety and depression were frequently registered alongside other MINI-identified diagnoses, but few patients had anxiety or depression diagnosed as a single comorbidity (25/189 [13\%] and 11/189 [6\%], respectively; Table 3). An autism diagnosis was recorded in 30/189 patients (16\%).

The majority of patients (108/189 [57\%]) had been prescribed pharmacological treatments for psychiatric 
Table 2 Patient demographics and clinical characteristics

\begin{tabular}{|c|c|c|c|}
\hline Characteristic & Danderyd $(n=101)$ & Liljeholmen $(n=88)$ & Overall $(N=189)$ \\
\hline \multicolumn{4}{|l|}{ Sex, $n(\%)$} \\
\hline Female & $61(60)$ & $46(52)$ & $107(57)$ \\
\hline Male & $40(40)$ & $42(48)$ & $82(43)$ \\
\hline$p$ value ${ }^{a}$ & & & 0.04 \\
\hline \multicolumn{4}{|l|}{ Age, years } \\
\hline Mean (SD) & $33.7(12.4)$ & $36.9(12.0)$ & $35.2(12.3)$ \\
\hline Median (range) & $30(18-72)$ & $36(18-66)$ & $33(18-72)$ \\
\hline$p$ value $^{\mathrm{b}}$ & & & 0.08 \\
\hline \multicolumn{4}{|l|}{ Confirmed ADHD diagnosis, $n(\%)$} \\
\hline Combined type ${ }^{c}$ & $57(56)$ & $57(65)$ & $114(60)$ \\
\hline Predominantly inattentive type ${ }^{d}$ & $37(37)$ & $12(14)$ & $49(26)$ \\
\hline Unspecified type ${ }^{e}$ & $7(7)$ & $19(21)$ & $26(14)$ \\
\hline \multicolumn{4}{|l|}{ DIVA 2.0, mean number of symptoms (SD) } \\
\hline Attention deficit ${ }^{f}(A 1)$ & $7.8(1.4)$ & $6.9(2.3)$ & $7.4(1.9)$ \\
\hline Hyperactivity/impulsivity ${ }^{\mathrm{g}}$ (A2) & $5.3(2.9)$ & $5.7(2.5)$ & $5.5(2.7)$ \\
\hline \multicolumn{4}{|l|}{ Highest level of education, $n(\%)$} \\
\hline Primary school & $36(36)$ & $33(38)$ & $69(37)$ \\
\hline Secondary school & $46(46)$ & $28(32)$ & $74(39)$ \\
\hline University & $11(11)$ & $13(15)$ & $24(13)$ \\
\hline Other ${ }^{h}$ & $8(8)$ & $14(16)$ & $22(12)$ \\
\hline \multicolumn{4}{|l|}{ Main source of income, $n(\%)$} \\
\hline Full- or part-time employment & $32(32)$ & $38(43)$ & $70(37)$ \\
\hline Self-employment (full- or part-time) & $9(9)$ & $9(10)$ & $18(10)$ \\
\hline Sickness benefit (short- or long-term) & $23(23)$ & $19(22)$ & $42(22)$ \\
\hline Unemployment benefit & $12(12)$ & $3(3)$ & $15(8)$ \\
\hline Other' & $25(25)$ & $19(22)$ & $44(23)$ \\
\hline \multicolumn{4}{|l|}{ Type of referral, $n(\%)$} \\
\hline Self-initiated & $27(27)$ & $13(15)$ & $40(21)$ \\
\hline School & $1(1)$ & $2(2)$ & $3(2)$ \\
\hline Primary care & $13(13)$ & $36(41)$ & $49(26)$ \\
\hline Psychiatric department & $56(55)$ & $28(32)$ & $84(44)$ \\
\hline Other & $4(4)$ & $7(8)$ & $11(6)$ \\
\hline Missing & $0(0)$ & $2(2)$ & $2(1)$ \\
\hline
\end{tabular}

ADHD attention-deficit/hyperactivity disorder, DIVA 2.0 Diagnostic Interview for ADHD in Adults, second edition, ICD-10-SE International Statistical Classification of Diseases and Related Health Problems - 10th Revision, Swedish modification, SD standard deviation

${ }^{a} X^{2}$ test was used to compare proportions of male and female patients between the two test sites

${ }^{b} t$-test was used to compare the mean ages of patients enrolled at the two test sites

'ICD-10-SE F90.0 B: ADHD, combined type

${ }^{d}$ ICD-10-SE F90.0 C: ADHD, predominantly inattentive type

ICD-10-SE F90.0 X: ADHD, unspecified ADHD

$\mathrm{f}_{n=163}$ (Danderyd, 91; Liljeholmen, 72)

$\mathrm{g}_{n}=157$ (Danderyd, 86; Liljeholmen, 71)

h'Other' includes occupational (7\%), other (4\%), and missing (1\%)

'OOther' includes 'studying/student loan' (7\%), 'other' (13\%), and 'missing' (4\%)

disorders. Medications included antidepressants $(67 / 189$ [35\%]), hypnotics (38/189 [20\%]), anxiolytics (37/189 [20\%]), and antipsychotics (5/189 [3\%]; Table 3). Three patients (3/189 [2\%]) had been prescribed ADHD medication (the central nervous system stimulant, osmotic-release oral system methylphenidate [OROS-MPH]) despite lacking a 
Table 3 Patients' psychiatric and somatic comorbidities and prescribed psychiatric medication

\begin{tabular}{|c|c|c|c|}
\hline Comorbidities & Danderyd $(n=101)$ & Liljeholmen $(n=88)$ & Overall $(N=189)$ \\
\hline \multicolumn{4}{|l|}{ Psychiatric, $n(\%)^{a}$} \\
\hline Any & $61(60)$ & $31(35)$ & $92(49)$ \\
\hline None & $40(40)$ & $57(65)$ & $97(51)$ \\
\hline \multicolumn{4}{|l|}{ Anxiety and/or depression, $n(\%)$} \\
\hline Anxiety & $43(43)$ & $22(25)$ & $65(34)$ \\
\hline Anxiety only ${ }^{\mathrm{b}}$ & $16(16)$ & $9(10)$ & $25(13)$ \\
\hline Depression $^{c}$ & $28(28)$ & $9(10)$ & $37(20)$ \\
\hline Depression only ${ }^{\mathrm{b}}$ & $7(7)$ & $4(5)$ & $11(6)$ \\
\hline Both anxiety and depression ${ }^{d}$ & $17(17)$ & $4(5)$ & $21(11)$ \\
\hline \multicolumn{4}{|l|}{ Other, $n(\%)$} \\
\hline Any other psychiatric diagnosis & $21(21)$ & $14(16)$ & $35(19)$ \\
\hline Dysthymic disorder & $5(5)$ & $4(5)$ & $9(5)$ \\
\hline Substance-related disorders & $6(6)$ & $2(2)$ & $8(4)$ \\
\hline Antisocial personality disorder & $4(4)$ & $3(3)$ & $7(4)$ \\
\hline Eating disorder & $5(5)$ & $1(1)$ & $6(3)$ \\
\hline Bipolar disorder & $4(4)$ & $1(1)$ & $5(3)$ \\
\hline Post-traumatic stress disorder & $3(3)$ & $1(1)$ & $4(2)$ \\
\hline \multicolumn{4}{|l|}{ Somatic comorbidity, n (\%) } \\
\hline Any & $86(85)$ & $59(67)$ & $145(77)$ \\
\hline None & $15(15)$ & $29(33)$ & $44(23)$ \\
\hline Pain & $25(25)$ & $11(13)$ & $36(19)$ \\
\hline Gastrointestinal disorders & $23(23)$ & $9(10)$ & $32(17)$ \\
\hline Allergy & $21(21)$ & $6(7)$ & $27(14)$ \\
\hline Asthma & $10(10)$ & $9(10)$ & $19(10)$ \\
\hline Joint problems & $6(6)$ & $6(7)$ & $12(6)$ \\
\hline Thyroid disease & $8(8)$ & $3(3)$ & $11(6)$ \\
\hline Lactose intolerance & $6(6)$ & $1(1)$ & $7(4)$ \\
\hline \multicolumn{4}{|l|}{ Prescribed psychiatric medication, $n$ (\%) } \\
\hline Any & $61(60)$ & $47(53)$ & $108(57)$ \\
\hline None & $40(40)$ & $41(47)$ & $81(43)$ \\
\hline Antidepressants & $37(37)$ & $30(34)$ & $67(35)$ \\
\hline Hypnotics & $24(24)$ & $14(16)$ & $38(20)$ \\
\hline Anxiolytics & $18(18)$ & $19(22)$ & $37(20)$ \\
\hline Antipsychotics & $3(3)$ & $2(2)$ & $5(3)$ \\
\hline Central nervous system stimulants & $3(3)$ & $0(0)$ & $3(2)$ \\
\hline
\end{tabular}

MINI Mini International Neuropsychiatric Interview

${ }^{a}$ Comorbid psychiatric diagnoses were based on MINI and did not include autism. An autism diagnosis was recorded in 30/189 patients (16\%)

${ }^{b}$ This disorder is listed as the only registered comorbidity

'Includes recurrent and single-episode depression

${ }^{\mathrm{d}} \mathrm{MINI}$-identified diagnosis of recurrent or single-episode depression and MINI-identified diagnosis of anxiety

confirmed ADHD diagnosis. Following ADHD diagnosis, pharmacological ADHD treatment was recommended for 146/189 patients (77\%). Most were prescribed OROS-MPH or other methylphenidate formulations (130/189 [69\%]), while atomoxetine and lisdexamfetamine dimesylate were prescribed to $8 / 189$ patients (4\%) and $5 / 189$ patients (3\%), respectively.

Somatic comorbidities affected $145 / 189$ patients (77\%) at enrolment. The most frequently reported conditions were pain $(36 / 189$ [19\%]), gastrointestinal disorders 
(32/189 [17\%]), and allergy (27/189 [14\%]; Table 3). Just over one-third of patients $(69 / 189$ [37\%]) had been prescribed medication for these comorbidities.

Patient-reported measures and HRQoL subgroup analyses The mean ASRS-v.1.1 Symptom checklist score in the study population was $47.4(\mathrm{SD}, 13.0)$, indicating that the majority of patients regularly experienced multiple ADHD symptoms (Table 4). Depressive symptoms were also common, as indicated by the mean MADRS-S score of 19.8 (SD, 9.2). The mean EQ-5D index score was 0.63 (SD, 0.28), indicating poor HRQoL in the study population.

Subgroup analysis was used to identify trends associated with low EQ-5D index scores (indicating poor HRQoL) in the patient population (Fig. 1). Mean EQ-5D index scores tended to be lower in older patients than in younger patients, with the lowest mean index score recorded in patients aged 50 years or above (Fig. 1). Other variables associated with low EQ-5D index scores included patient-rated severe depressive symptoms (MADRS-S score $\geq 30$ ), an ASRS-v.1.1 score of 60 or greater, and having multiple comorbid psychiatric disorders.

\section{HRQoL predictor analysis}

In the multivariate regression model, a high MADRS-S score $(\geq 30)$ was the strongest predictor of low EQ-5D index scores (adjusted mean, $-0.40 ; P<0.001$, compared with scores between 1 and 11; Fig. 2). MINI-identified anxiety and depression $(P<0.001)$ and having three or more MINI-identified diagnoses $(P=0.002)$ were also strong predictors, compared with having no MINI-identified diagnoses (Fig. 2).

Adjusted mean EQ-5D index scores were significantly higher in men than in women $(P=0.049)$, in patients with secondary education than in those without $(P=0.004)$, and in patients whose main income source was full- or part-time employment, compared with those reliant on other sources $(P=0.03$, Fig. 2). Adult ASRS-v.1.1 Symptom checklist or
DIVA 2.0 scores were not significant predictors of EQ-5D index score $(P \geq 0.05$; Fig. 2$)$.

Almost one quarter (22\%) of the patient population had a WAIS-IV score of $<85$ but there was no significant association between high WAIS-IV scores and HRQoL.

\section{Discussion}

Adult patients with newly diagnosed ADHD experienced a considerable disease burden and substantially impaired HRQoL in this retrospective chart review. Psychiatric comorbidities were common in the study population, and linear regression analysis identified comorbid anxiety and depression as key factors contributing to poor HRQoL. MADRS-S score was the strongest predictor of EQ-5D index score, implying an association between severe depression and poor HRQoL in adult patients with ADHD. Other variables, including low educational attainment, low levels of employment, and female sex were also associated with poor HRQoL in the study population.

Both the strengths and weaknesses of this study should be considered when interpreting the results. The study included a moderately large number of patients and integrated in-depth analyses of patients' neuropsychiatric evaluations with a variety of patient- and clinician-reported measures, including HRQoL. The variety of information extracted from the EMRs enabled the investigation of a wide range of potential factors impacting $\mathrm{HRQoL}$ in adult patients with ADHD. HRQoL was assessed using the EQ-5D, a validated generic HRQoL tool that provides health utility estimates and is recommended by the UK National Institute for Health and Care Excellence [22]. The use of the generic EQ-5D permits comparisons with reference populations and patients with other diseases [22].

There are, however, several limitations that should be noted. First, data for some parameters were missing for a substantial proportion of patients, which may have introduced bias. To address this, a multiple imputation

Table 4 Patient-reported measures of ADHD symptoms, depression, and HRQoL

\begin{tabular}{|c|c|c|c|c|c|c|}
\hline \multirow[t]{2}{*}{ Measure } & \multicolumn{2}{|c|}{ Danderyd $(n=101)$} & \multicolumn{2}{|c|}{ Liljeholmen $(n=88)$} & \multicolumn{2}{|c|}{ Overall $(N=189)$} \\
\hline & $\bar{n}$ & Mean (SD) & $\bar{n}$ & Mean (SD) & $n$ & $\overline{\text { Mean (SD) }}$ \\
\hline \multicolumn{7}{|l|}{ ASRS-v1.1 score } \\
\hline Screener & 1 & - & 65 & $5.0(1.0)$ & 66 & $5.0(1.0)$ \\
\hline Symptom checklist & 98 & $46.4(13.0)$ & 11 & $56.6(8.7)$ & 109 & $47.4(13.0)$ \\
\hline MADRS-S score ${ }^{a}$ & 93 & $20.3(9.6)$ & 72 & $19.1(8.5)$ & 165 & $19.8(9.2)$ \\
\hline \multicolumn{7}{|l|}{ EQ-5D } \\
\hline Index score & 95 & $0.64(0.27)$ & 67 & $0.61(0.30)$ & 162 & $0.63(0.28)$ \\
\hline VAS & 91 & $58.1(21.2)$ & 66 & $56.4(23.5)$ & 157 & $57.4(22.1)$ \\
\hline
\end{tabular}

$A D H D$ attention-deficit/hyperactivity disorder, $A S R S-v 1.1$ Adult ADHD Self-Report Scale version 1.1, EQ-5D five-dimension EuroQol questionnaire, $H R Q$ oL health-related quality of life, MADRS-S Montgomery-Åsberg Depression Rating Scale - Self-reported, PHQ-9 Patient Health Questionnaire 9, SD standard deviation, VAS visual analog scale

${ }^{a}$ MADRS-S scores were converted from PHQ-9 scores for 72 patients from Liljeholmen and one patient from Danderyd using a regression equation (MADRS-S $=[1.206 \times$ PHQ-9 $]+4.062$ ) 


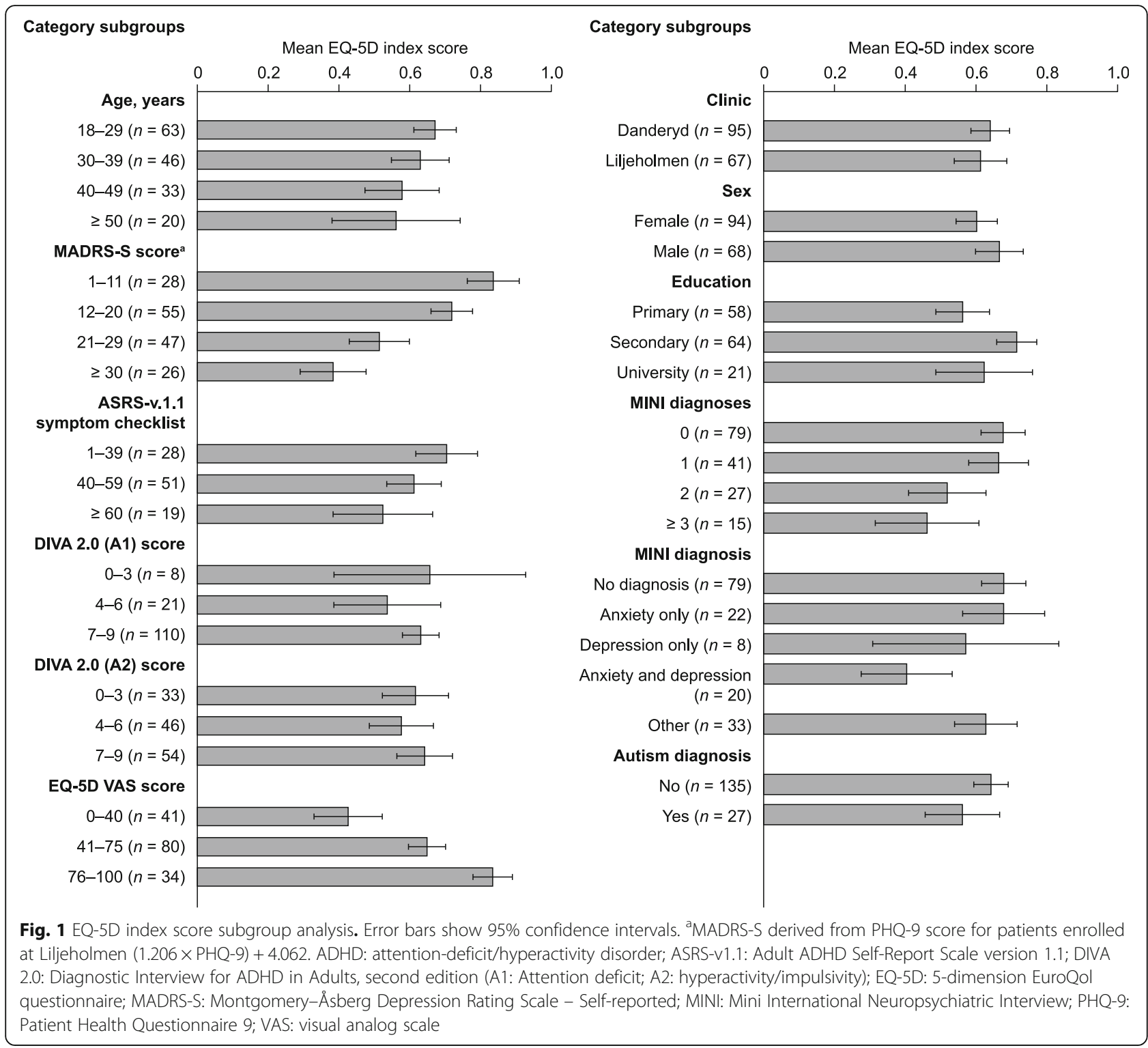

model was utilized to estimate missing data for the regression model. However, this method may also influence results, particularly when sample sizes are limited. Data were missing for fewer than $20 \%$ of the total patients across both sites for all imputed variables except ASRS-v.1.1 score, which was missing for $88 \%$ of Liljeholmen patients (Additional file 1: Table S1). This implies that the ASRS-v.1.1 may not be part of the routine diagnostic procedure at Liljeholmen. The high proportion of imputed data for this variable in the linear regression model precludes any reliable conclusions concerning the relationship between ASRS-v.1.1 score and HRQoL in adult patients with ADHD. Secondly, covariates for the statistical models were selected based on the data available, but other factors influencing HRQoL may not have been captured in the study. Thirdly, comorbid psychiatric diagnoses were based on the MINI for all psychiatric disorders except autism. Inclusion of autism as a separate covariate in the analyses may have led to underestimation of the impact of psychiatric comorbidities on patients' HRQoL. Other limitations to consider are the absence of a comparative control sample of EQ-5D index scores from the Swedish population and the recruitment of patients only in the city of Stockholm.

The findings of the present study strongly suggest that adult patients with ADHD experience reduced HRQoL, and support the conclusion that the manifestations of ADHD are associated with considerable disease burden. The mean EQ-5D index score in the patient population was 0.63 (SD, 0.28), which is markedly lower than published EQ-5D index scores for the healthy adult population in Sweden (range, 0.74-0.89) [23] and in the UK 


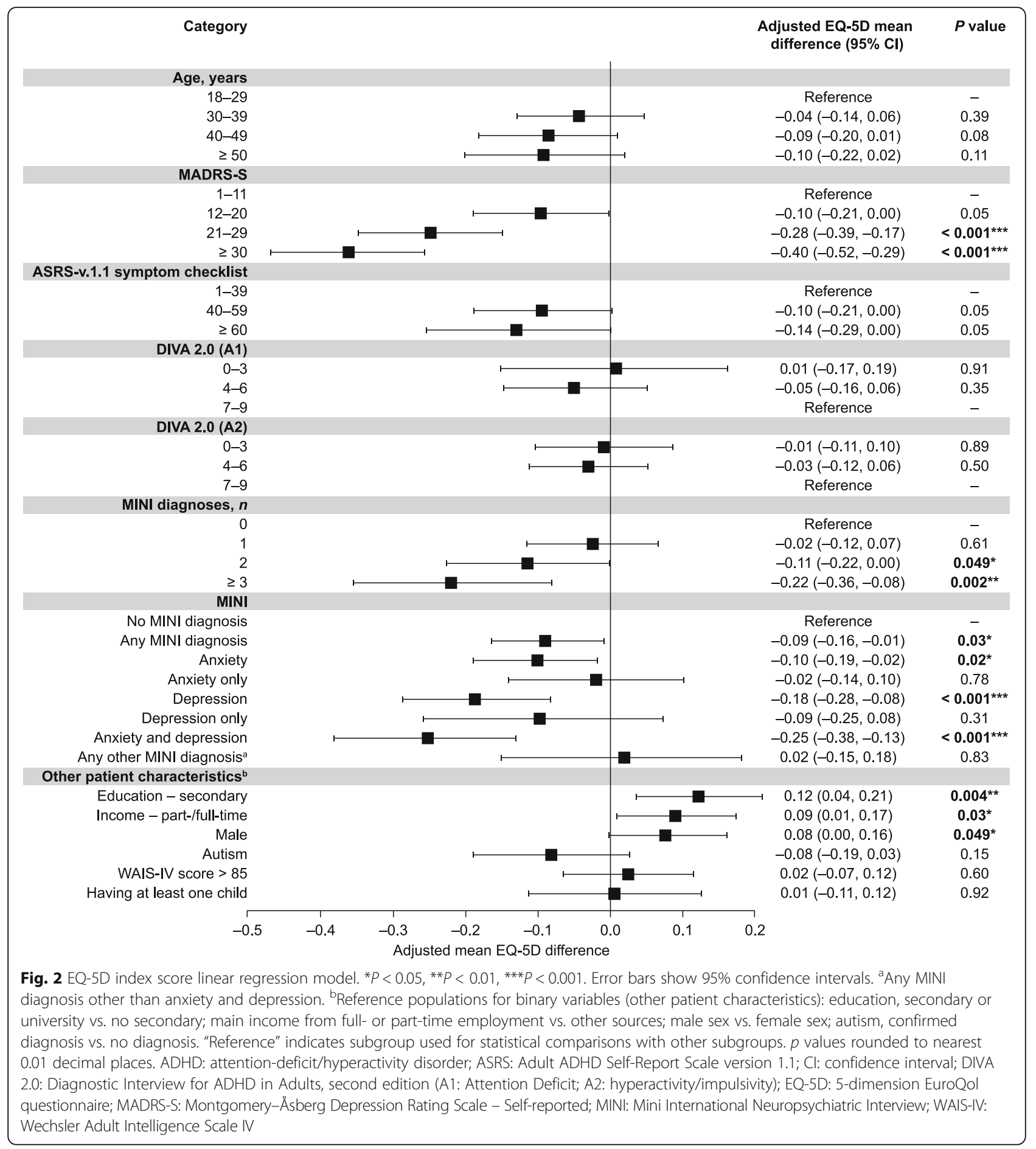

(mean, 0.86; SD, 0.28) [24]. Similarly, low EQ-5D index scores have been reported for patients with other chronic conditions including asthma, chronic obstructive pulmonary disease, diabetes, epilepsy, heart failure, and stroke (overall mean index score, 0.73) [25]. The mean EQ-5D index score in the present study is also within the range reported in a systematic review of HRQoL in adults with psoriasis (0.52-0.9) [26], but higher than that reported for people with spinal complaints (0.39) [27]. The applicability of the present study's findings to cultural/ social groups outside Stockholm is uncertain, although a recent study involving seven countries concluded that the impact of ADHD on patient well-being is consistent across different socioeconomic groups [13]. Furthermore, the EQ-5D scores in the present study are similar to those reported for adult patients with ADHD in other European 
countries [28, 29], suggesting a broad relevance of the present findings.

To our knowledge, this is the first study to use linear regression to identify specific factors that may influence HRQoL in adult patients with ADHD. Comorbid anxiety and depression, together with patient-rated severe depressive symptoms, were identified as the strongest predictors of poor HRQoL. Given that these diagnoses are frequently comorbid with ADHD, the potential negative impact of these disorders upon patients' HRQoL should be considered in their clinical management. Adjusted mean EQ-5D index scores were also significantly higher in men than in women, who made up $57 \%$ of the patient population. A preponderance of women is uncommon in studies of ADHD, which is diagnosed more frequently in men than in women [2]. Gender is not thought to modulate the phenotypic presentation of ADHD [30], but higher rates of comorbid anxiety disorders have been reported in women than in men [31], which could contribute to the gender difference in HRQoL in the present study.

Psychiatric disorders other than depression and anxiety were common, affecting $19 \%$ of the patient population. However, only $3 \%$ of the patients in the present study were diagnosed with comorbid bipolar disorder. This is in contrast with the results of the National Comorbidity Study which reported a bipolar disorder prevalence of $19.4 \%$ among adults with ADHD [32]. It is possible that the unusually low frequency of bipolar disorder may have influenced the relationship between comorbid psychiatric disorders and HRQoL in the present study, and further studies in patients with comorbid bipolar disorder may be warranted. Over two-thirds of the patient population (77\%) also reported at least one somatic comorbidity. Pain was the most frequently reported somatic comorbidity. Individuals with ADHD are more prone to accidents and injuries [33], may be more sensitive to pain [34], and may experience motor inhibition problems and heightened muscle tone [35]. Multiple studies have identified a high incidence of joint hypermobility in individuals with ADHD [36], which may also have contributed to the high prevalence of pain in the present study. Adults with ADHD are more likely to have somatic disorders, and are more likely to use non-psychiatric healthcare services, than those without ADHD [37]. In particular, somatic disorders such as obesity, sleep disorders, and asthma frequently co-occur with ADHD [38]. ADHD symptoms and functional impairment may make people with ADHD more vulnerable to somatic diseases and may affect their ability to obtain appropriate diagnosis and treatment for somatic disease. Optimum care for patients with ADHD may involve an integrated and multidisciplinary approach for identifying and treating co-occurring psychiatric and somatic disorders [39].
Other predictors of poor HRQoL included poor educational achievement and not having a main income derived from employment. In the present study, primary school was the highest level of education reached for $37 \%$ of adults with newly diagnosed ADHD, and only $13 \%$ were educated to university level. In comparison, equivalent levels in the general Stockholm population in 2014 were reported to be 16 and $45 \%$, respectively [40]. Having an average or higher intelligence score (denoted by a WAIS-IV score of more than 85 ) was not significantly associated with improved HRQoL, implying that the challenges faced by patients with ADHD in school extend beyond deficits in intellectual functioning. The present results also suggest that difficulties continue into the workplace. Despite a median age of 33 years, fewer than half of the patients were able to support themselves financially through employment or self-employment, and $22 \%$ were reliant on sickness benefit as their main source of income. Thus, the present study highlights the significant impact that poor performance in school and the workplace can have on HRQoL and emphasizes the need for early diagnosis and effective clinical management of ADHD symptoms from a young age. The present study was not designed to investigate the impact of ADHD medication on HRQoL in individuals with ADHD, but a recent systematic review concluded that ADHD medication may help to reduce functional impairment and to improve HRQoL deficits [41].

European guidelines recommend an individualized, multimodal approach to treatment of ADHD in adults, including psychological treatments and medication [12]. In the present study, over two-thirds (77\%) of patients were prescribed pharmacological treatment for ADHD. This figure is in line with guidance from the Swedish National Board of Health and Welfare indicating that ADHD medication is likely to be effective and appropriate in the majority of patients [42].

\section{Conclusions}

In summary, the findings of this non-interventional, retrospective study indicate that undiagnosed ADHD contributes to poor HRQoL in adults presenting with psychiatric symptoms. Furthermore, the impact of ADHD on HRQoL may be exacerbated by psychiatric comorbidities such as anxiety and depression. Adults with newly diagnosed ADHD and comorbid depression or anxiety may require particular care and resources in their management.

\section{Additional file}

Additional file 1: Table S1. Proportion of patients with missing data. (DOCX $16 \mathrm{~kb}$ ) 


\section{Abbreviations}

ADHD: Attention-deficit/hyperactivity disorder; ASRS-v1.1: Adult ADHD SelfReport Scale version 1.1; DIVA 2.0: Diagnostic Interview for ADHD in Adults, second edition (A1: Attention deficit; A2: Hyperactivity/impulsivity); EQ-5D: 5dimension EuroQol questionnaire; HRQoL: Health-related quality of life; MADRS-S: Montgomery-Åsberg Depression Rating Scale - Self-reported; MINI: Mini International Neuropsychiatric Interview; PHQ-9: Patient Health Questionnaire 9; SD: Standard deviation; VAS: Visual analogue scale; WAISIV: Wechsler Adult Intelligence Scale IV

\section{Acknowledgements}

The authors thank the patients and investigators involved in the study. Under the direction of the authors, Dr. M. Cottingham and Dr. K. Dodd of Oxford PharmaGenesis, Cardiff, UK, provided writing assistance for this publication. Editorial assistance in formatting, proofreading, and copyediting the manuscript, fact-checking, and coordination and collation of comments was also provided by Oxford PharmaGenesis. Shire International $\mathrm{GmbH}$ provided funding to Oxford PharmaGenesis for support in writing, editing, and managing this manuscript.

\section{Funding}

This study was funded by Shire Sweden AB. Shire International GmbH provided funding to Oxford PharmaGenesis for support in writing, editing, and managing this manuscript. Shire also reviewed and edited the manuscript for scientific accuracy. Although employees of Shire were involved in the design, collection, analysis, interpretation, and fact-checking of the information, the authors produced the content for this paper, interpreted the data, and decided on the submission of the manuscript for publication in BMC Psychiatry independently.

\section{Availability of data and materials}

The datasets used and/or analysed during the current study are available from the corresponding author on reasonable request.

\section{Authors' contributions}

$E A, A F, E M, J S$, and $Y G$ developed the study concept and design. EA, MD, EM, $J S$, and YG were responsible for data acquisition, analysis, and interpretation. $E A, M D, A F, E M, J S$, and YG developed, reviewed, and edited the manuscript content for important intellectual content. All authors approved the final manuscript version.

\section{Ethics approval and consent to participate}

The study was approved by the Regional Ethical Review Board in Stockholm and the need for consent was waived due to the retrospective nature of the study. The study was conducted in accordance with the ethical standards of the World Medical Association Declaration of Helsinki. The data-gathering form was based on the recommendations for neuropsychiatric investigations of patients with suspected ADHD described in recent guidelines (mww.psykiatristid.se) and validated by a clinical expert.

\section{Consent for publication}

Not applicable.

\section{Competing interests}

Dr. Ewa Ahnemark is an employee of Shire and owns stock or stock options. The following authors have received compensation for serving as consultants or speakers for, or they or the institutions they work for have received research support or royalties from, the companies or organizations indicated: Dr. Marianne Di Schiena (Prima Child and Adult Psychiatry AB); Dr. Anne-Christine Fredman (Evolan, Lilly, Novartis, Servier, and Shire); Dr. Emma Medin (PAREXEL International); Dr. Jonas. K. Söderling (COMBINE Sweden, Novo Nordisk, and PAREXEL International); Dr. Ylva Ginsberg (Eli Lilly, HB Pharma, Janssen-Cilag, Lundbeck, and Novartis).

\section{Publisher's Note}

Springer Nature remains neutral with regard to jurisdictional claims in published maps and institutional affiliations.

\section{Author details}

${ }^{1}$ Shire, Vasagatan 7, SE-111 20 Stockholm, Sweden. ${ }^{2}$ Prima Child and Adult Psychiatry AB, Stockholm, Sweden. ${ }^{3}$ PAREXEL International, Stockholm,
Sweden. ${ }^{4}$ Department of Learning, Informatics, Management and Ethics, Karolinska Institute, Stockholm, Sweden. ${ }^{5}$ Bell Analytics, Stockholm, Sweden. ${ }^{6}$ Department of Medical Epidemiology and Biostatistics, Karolinska Institute, Stockholm, Sweden. ${ }^{7}$ Department of Clinical Neuroscience, Centre for Psychiatry Research, Karolinska Institute, Stockholm, Sweden. ${ }^{8}$ Present Address: Psychiatry Centre, Stockholm County Council, Södertälje, Sweden.

Received: 6 February 2018 Accepted: 27 June 2018

Published online: 13 July 2018

\section{References}

1. Goodman DW, Mitchell S, Rhodewalt L, Surman CB. Clinical presentation, diagnosis and treatment of attention-deficit hyperactivity disorder (ADHD) in older adults: a review of the evidence and its implications for clinical care. Drugs Aging. 2016;33(1):27-36.

2. Willcutt EG. The prevalence of DSM-IV attention-deficit/hyperactivity disorder: a meta-analytic review. Neurotherapeutics. 2012;9:490-9.

3. Simon V, Czobor P, Balint S, Meszaros A, Bitter I. Prevalence and correlates of adult attention-deficit hyperactivity disorder: meta-analysis. $\mathrm{Br} J$ Psychiatry. 2009;194:204-11.

4. Biederman J. Advances in the neurobiology of ADHD. CNS Spectrums. 2007;12:6-7.

5. Faraone SV, Biederman J, Mick E. The age-dependent decline of attention deficit hyperactivity disorder: a meta-analysis of follow-up studies. Psychol Med. 2006;36:159-65.

6. Nylander L, Holmqvist M, Gustafson L, Gillberg C. ADHD in adult psychiatry. Minimum rates and clinical presentation in general psychiatry outpatients. Nord J Psychiatry. 2009;63:64-71.

7. Ginsberg Y, Hirvikoski T, Lindefors N. Attention deficit hyperactivity disorder (ADHD) among longer-term prison inmates is a prevalent, persistent and disabling disorder. BMC Psychiatry. 2010;10:112.

8. Agnew-Blais JC, Polanczyk GV, Danese A, Wertz J, Moffitt TE, Arseneault L. Evaluation of the persistence, remission, and emergence of attention-deficit/ hyperactivity disorder in young adulthood. JAMA Psychiatry. 2016;73:713-20.

9. Caye A, Rocha T, Anselmi L, et al. Attention-deficit/hyperactivity disorder trajectories from childhood to young adulthood: evidence from a birth cohort supporting a late-onset syndrome. JAMA Psychiatry. 2016;73:705-12.

10. Giacobini M, Medin E, Ahnemark E, Russo LJ, Carlqvist P. Prevalence, patient characteristics, and pharmacological treatment of children, adolescents, and adults diagnosed with ADHD in Sweden. J Atten Disord. 2014; https://doi. org/10.1177/1087054714554617.

11. Nylander L, Holmqvist M, Gustafson L, Gillberg C. Attention-deficit/ hyperactivity disorder (ADHD) and autism spectrum disorder (ASD) in adult psychiatry. A 20-year register study. Nord J Psychiatry. 2013;67:344-50.

12. Kooij SJ, Bejerot S, Blackwell A, Caci H, Casas-Brugué M, Carpentier PJ, et al. European consensus statement on diagnosis and treatment of adult ADHD: the European network adult ADHD. BMC Psychiatry. 2010;10:67.

13. Brod M, Pohlman B, Lasser R, Hodgkins P. Comparison of the burden of illness for adults with ADHD across seven countries: a qualitative study. Health Qual Life Outcomes. 2012;10:47.

14. Brod M, Schmitt E, Goodwin M, Hodgkins P, Niebler G. ADHD burden of illness in older adults: a life course perspective. Qual Life Res. 2012;21:795-9.

15. Gusi N, Olivares PR, Rajendram R. The EQ-5D health-related quality of life questionnaire. In: Preedy VR, Watson RR, editors. Handbook of disease burdens and quality of life measures. New York: Springer New York; 2010. p. 87-99.

16. World Health Organization. International statistical classification of diseases and related health problems, tenth revision. Geneva: World Health Organization; 2010.

17. Adler L, Kessler RC, Spencer T. Adult ADHD self-report scale-v1. 1 (ASRS-v1. 1) symptom checklist. New York: World Health Organization; 2003.

18. Lecrubier Y, Sheehan DV, Weiller E, Amorim P, Bonora I, Harnett Sheehan K, et al. The Mini international neuropsychiatric interview (MINI). A short diagnostic structured interview: reliability and validity according to the CIDI. Eur Psychiatry. 1997;12:224-31

19. American Psychiatric Association. Diagnostic and statistical manual of mental disorders. 4th ed., text revision. Washington DC: American Psychiatric Association; 2000

20. Fantino B, Moore N. The self-reported Montgomery-Åsberg depression rating scale is a useful evaluative tool in major depressive disorder. BMC Psychiatry. 2009;9:26. 
21. Hawley CJ, Gale TM, Smith PS, Jain S, Farag A, Kondan R, et al. Equations for converting scores between depression scales (MADRS, SRS, PHQ-9 and BDIII): good statistical, but weak idiographic, validity. Hum Psychopharmacol. 2013;28:544-51.

22. NICE. Guide to the methods of technology appraisal 2013. National Institute for health and care excellence; 2013. Retrieved from: http://publications. nice.org.uk/pmg9.

23. Burstrom $K$, Johannesson $M$, Diderichsen $F$. Swedish population healthrelated quality of life results using the EQ-5D. Qual Life Res. 2001;10:621-35.

24. Kind P, Hardman G, Macran S. UK Population Norms for EQ-5D. University of York Centre for Health Economics Discussion Paper: 1721999.

25. Peters $M$, Crocker $H$, Jenkinson C, Doll H, Fitzpatrick R. The routine collection of patient-reported outcome measures (PROMs) for long-term conditions in primary care: a cohort survey. BMJ Open. 2014;4:e003968.

26. Moller AH, Erntoft S, Vinding GR, Jemec GB. A systematic literature review to compare quality of life in psoriasis with other chronic diseases using EQ-5Dderived utility values. Patient Relat Outcome Meas. 2015;6:167-77.

27. McDonough CM, Grove MR, Tosteson TD, Lurie JD, Hilibrand AS, Tosteson AN. Comparison of EQ-5D, HUI, and SF-36-derived societal health state values among spine patient outcomes research trial (SPORT) participants. Qual Life Res. 2005;14:1321-32.

28. Karlsdotter K, Bushe C, Hakkaart L, Sobanski E, Kan CC, Lebrec J, et al. Burden of illness and health care resource utilization in adult psychiatric outpatients with attention-deficit/hyperactivity disorder in Europe. Curr Med Res Opin. 2016;32:1547-56.

29. van Hout B, Janssen MF, Feng YS, Kohlmann T, Busschbach J, Golicki D, et al. Interim scoring for the EQ-5D-5L: mapping the EQ-5D-5L to EQ-5D-3L value sets. Value Health. 2012;15:708-15.

30. Biederman J, Faraone SV, Monuteaux MC, et al. Gender effects on attentiondeficit/hyperactivity disorder in adults, revisited. Biol Psychiatry. 2004;55:692-700.

31. Wilens TE, Biederman J, Faraone SV, Martelon M, Westerberg D, Spencer TJ. Presenting ADHD symptoms, subtypes, and comorbid disorders in clinically referred adults with ADHD. J Clin Psychiatry. 2009;70:1557-62.

32. Kessler RC, Adler L, Barkley R, Biederman J, Conners CK, Demler O, Faraone SV, Greenhill LL, Howes MJ, Secnik K, et al. The prevalence and correlates of adult ADHD in the United States: results from the National Comorbidity Survey Replication. Am J Psychiatry. 2006;163:716-23.

33. Swensen A, Birnbaum HG, Ben Hamadi R, Greenberg P, Cremieux PY, Secnik $\mathrm{K}$. Incidence and costs of accidents among attention-deficit/hyperactivity disorder patients. J Adolesc Health. 2004;35:346.e1-9.

34. Roi T, Elon E, Naor D, Dorit P. Alterations in pain response are partially reversed by methylphenidate (Ritalin) in adults with attention deficit hyperactivity disorder (ADHD). Pain Practice. 2015;15:4-11.

35. Stray LL, Kristensen $\varnothing$, Lomeland M, Skorstad M, Stray T, Tønnessen FE. Motor regulation problems and pain in adults diagnosed with ADHD. Behav Brain Funct. 2013;9:18.

36. Baeza-Velasco C, Grahame R, Bravo JF. A connective tissue disorder may underlie ESSENCE problems in childhood. Res Dev Disabil. 2017;60:232-42.

37. Hodgkins P, Montejano L, Sasané R, Huse D. Cost of illness and comorbidities in adults diagnosed with attention-deficit/hyperactivity disorder: a retrospective analysis. Prim Care Companion CNS Disorders. 2011;13:e1-e12.

38. Instanes JT, Klungsøyr K, Halmøy A, Fasmer OB, Haavik J. Adult ADHD and comorbid somatic disease: a systematic literature review. J Atten Disord. 2016; https://doi.org/10.1177/1087054716669589.

39. Muskens JB, Velders FP, Staal WG. Medical comorbidities in children and adolescents with autism spectrum disorders and attention deficit hyperactivity disorders: a systematic review. Eur Child Adolesc Psychiatry. 2017;26:1093-103.

40. Statistics Sweden: http://www.scb.se/. Accessed 19 May 2017.

41. Coghill DR, Banaschewski T, Soutullo C, Cottingham MG, Zuddas A. Systematic review of quality of life and functional outcomes in randomized placebo-controlled studies of medications for attention-deficit/hyperactivity disorder. Eur Child Adolesc Psychiatry. 2017;26:1283-307.

42. The National Board of Health and Welfare. Pharmacological treatment of ADHD in children and adults. Sweden; 2015.

\section{Ready to submit your research? Choose BMC and benefit from:}

- fast, convenient online submission

- thorough peer review by experienced researchers in your field

- rapid publication on acceptance

- support for research data, including large and complex data types

- gold Open Access which fosters wider collaboration and increased citations

- maximum visibility for your research: over $100 \mathrm{M}$ website views per year

At BMC, research is always in progress.

Learn more biomedcentral.com/submissions 